\title{
Transforming Foreign Language Grammar Classes through Teacher Training: An Experience from Nepal
}

\author{
Kamal Kumar Poudel ${ }^{1, *}$ \\ ${ }^{1}$ Department of English Language Education, Tribhuvan University, Mahendra Ratna Campus, Tahachal, \\ Kathmandu, Nepal \\ *Correspondence: Department of English Language Education, Tribhuvan University, Mahendra Ratna Campus, \\ Tahachal, Kathmandu, Nepal. Tel: 977- 984-263-5465. E-mail: kkpoudel2023@gmail.com
}

Received: January 28, 2018

Accepted: February 10, $2018 \quad$ Online Published: February 23, 2018

doi:10.5430/wje.v8n1p86

URL: https://doi.org/10.5430/wje.v8n1p86

\begin{abstract}
In Nepal, unlike elsewhere, local studies have almost continually suggested that there has not been adequate reflection of the teacher training output in the real classroom situation. English teachers commonly blame on the unfavourable environment as the main obstacle to the successful classroom application of their knowledge and skills needed for teaching English as a foreign language (EFL) gained from professional development programmes. The pre-training observations of a secondary level EFL teacher's four classes made the basis of a case study for this research. Stemming from the case study, three techniques were used as a process of action research: i) the need-based refresher training (along with other participants) as an intervention ii) the post-training class observations (in a demonstration class), and iii) informal post-class talks. Thus, this study was an attempt to examine through action research germinating from a case study, whether (and to what degree), the output of the Teachers' Professional Development refresher training (TPD refresher) would be transferred to the actual classroom situation. The pre-training and post-training observations were compared and contrasted to reach the conclusion. The results suggest that the output would be reflected to a large degree in the classroom provided that the training is need-based. Thus, it was concluded that if (foreign) (Note 1) language teachers are properly equipped with professional knowledge and skills through need-based training, (foreign) language classes are very likely to be transformed as desired.
\end{abstract}

Keywords: TPD refresher, examples first, lenses, incubation, paradigm shift

\section{Introduction}

Finland has long been so successful in the quality of education in terms of student achievement that it is often recognized as "one of the internationally acknowledged educational superpowers" (Uusiautti \& Määttä, 2013 p. 12). For this, most credit goes to teacher training and its successful classroom application. However, in Nepal, despite several attempts, a considerable amount of time, money and other resources invested in this field since the 1970 s, the experiences have not been satisfactory enough in terms of their classroom application for better educational quality. In Nepal, as reported, most of the teachers (98.2\%) were equipped with professional qualifications prior to 2009 (National Centre for Educational Development-NCED, 2009). However, there has been an unexpectedly low application (50\%) of teacher training to the actual classroom situation (Research Centre for Educational Innovation and Development CERID, 2005, as mentioned in NCED, 2009). This comparatively less encouraging scenario of teacher training in the Nepalese context raised some crucial questions to be answered through research:

1) Do the teachers fail to apply what they have gained through their professional training (as generally stated and reported)?

2) If yes, what is/are the reason(s) behind it?

This study was set out to answer such questions by deriving results from the area of teaching grammar. 


\section{The Context and the Case}

As a roster trainer under an educational training centre (ETC), I was supposed to lead a few sessions of the five-day need-based TPD refresher for secondary level English teachers to be conducted from 31 May 2011. As part of planning the TPD refresher I, among other trainers, was involved in sorting out/categorizing the needs collected from the secondary level English teachers a month before it began. As soon as the sorting process had terminated, the contents for the refresher were collectively determined. As allotted by the schedule, I was supposed to deal with a session regarding teaching grammar in which a key query was: "Which method of teaching grammar should be adopted- deductive or inductive- or still any other methods?" (one made by a to-be participant, coded as Mr. B here, not to mention his name for some ethical reason). I knew that Mr. B, who had been registered as a participant for the forthcoming five-day refresher, was an English teacher from a school not very far for me to visit if I wished to plan an observation to see how in reality he was teaching grammar- and so, to explore what his actual problems were. I planned a case study for which the main technique would be class observation.

Upon his consent, I observed four of his classes, of which the last one typically depicted a comprehensive picture of his teaching a grammar point in Grade 9, namely, 'the simple present tense'. As I explored, most of his grammar teaching activities started with so-called rules before examples (see Appendix 1).

A week later in the refresher session, where Mr. B was one of the participants, I presented (i.e. demonstrated 'models') trying my best to be guided by the 'examples first' and the 'rule first' patterns, one after the other, within the framework of the PPP (Presentation, Practice and Production) procedure.

Then at the end of the session, there was a short feedback-and-reflection period for the participants to comment on the presentation. As expected, most of the participants preferred the 'examples first' presentation to the 'rule first' one. Yet, most of them complained that the English classes in their respective schools were not a favourable environment to apply the 'examples first' pattern. What they had implied by the 'unfavourable environment' was partly the 'low proficiency level' of their students in English, and partly the 'current socio-political situation' of the society outside of school. However, a few of the others, including Mr. B, opined that the application of the 'examples first' pattern would be a possibility if tried properly and patiently.

It was Mr B. who earlier had inquired, "Which method of grammar should be...?" and reflected in favour of the 'examples first' pattern after his (their) observation of the demonstrations in the training session. Inspired by this, I further planned to observe him teaching a grammar point (of course the same as in the case study) in his real workplace (classroom), and actualized the plan leaving a reasonable interval (a month) after the completion of the TPD refresher.

\section{Literature Review and Conceptual Framework}

The study moved around two themes: language teacher training and teaching grammar, where the latter emerged from the former in the course of the study. Therefore, these two themes are specially considered in this section. Finally, a conceptual framework has also been derived.

\section{Review of the relevant literature}

A review of the literature related to teacher training and teaching grammar are presented under this heading.

Teacher training. In this sub-heading, the theory and models of (foreign) language teacher training underpinning this study are reviewed first, followed by the review of some relevant empirical studies.

Theory and models of language teacher training. One proponent who comprehensively explains how teacher training contributes to professional expertise/competence is Michael J. Wallace. To begin with, Wallace (2010) distinguishes between teacher training/education and development thus: "training or education is something that can be presented or managed by others; whereas development is something that can be done by and for oneself" (p. 3). Wallace (2010) suggests that, like other professionals, teachers too can develop their professionalism in three major models of professional education: the 'craft' model, the applied science model and the reflective model.

According to Wallace (2010, p. 6), the 'craft' model assumes that "the wisdom of the profession resides in an experienced professional practitioner: someone who is expert in the practice of the 'craft'." Following this model, the young practitioner develops his/her professional competence by imitating the expert's techniques and advice. This model, therefore, assumes the dwelling of a vast gap of knowledge and skills between the knower (trainer) and the novice (trainee).

Judging from the current sense of teacher development, this model has some problems. First, as Wallace points out, 
it equates teaching to the craft of metallurgy (making metals) where apprentices learn from masters. This analogy only partially explains the nature of teaching and learning. Secondly, it holds a static view which does not recognize how people think and behave.

Though a traditional one, the 'applied science model' is still popularly prevalent as far as the training/education for professionals is the consideration. This model assumes that one can solve teaching problems by the application of empirically obtained research findings. Wallace (2010) remarks, "Within this framework practical knowledge of anything is simply a matter of relating the most appropriate means to whatever objectives are decided on. The whole issue of the practice of a profession is therefore merely instrumental" (p. 8). This is in a way a producer-and-applier model of professional training/education. Again in this model, too, experts have a key role in that they convey the findings of scientific knowledge, usually the outcomes of research and experiments, to the trainee who transfers them to the classroom. Therefore, the failure in the trainees' action is perhaps the result of either the failure in their proper understanding of the findings or the failure in proper application of the findings.

This double-beneficiaries model also inherits some weaknesses. First, like in the 'craft' model, there is a divide between the 'thinkers' and the 'doers': it separates the 'experts' from the 'technicians'/practitioners (Wallace, 2010). Therefore, since this model neglects the 'knowing in action' and its reflection, it can only hardly address the actual needs and interests of the real practitioner. Secondly, as a limitation, not all empirical findings from education-related fields may be capable of being applied to all kinds of pedagogic issues on one hand, and, on the other hand, not all pedagogic issues and problems can be solved by the findings of empirically-based research already made available by experts.

Regarding the 'reflective' model, Wallace (2010) claims that professional knowledge is confined to the professionals of the given field. He further categorizes professional knowledge into 'received knowledge' and 'experiential knowledge' (p. 12). According to him, 'received knowledge' is the knowledge of research-related facts, data and theories and is often represented largely in teacher education programmes. In contrast, 'experiential knowledge' is acquired as 'knowing-in-action'. 'Knowing-in-action' involves skills and phenomena recognized and used in the course of day-to-day practice but not necessarily explained in terms of description, rules and procedures.

A teacher is sometimes heard of saying "it [a certain procedure] did not seem to be working well, so I switched to something else" (Wallace, 2010, p. 13). So, Wallace claims that teachers' experiential knowledge, or 'knowing-in-action' can be developed into systematic insights by means of their own reflection. He argues:

It is (or should be) normal for professionals to reflect on their professional performance, particularly when it goes especially well or especially badly. They will probably ask themselves what went wrong or why it went so well. They will probably want to think about what to avoid in the future, and what to repeat and so on. (p. 13)

Wallace (2010) proposes that 'structured professional education' should include two kinds of knowledge development: received knowledge and experiential knowledge. For a foreign language teacher, received knowledge would include the acquaintance with vocabulary, matching concepts, research findings, theories and skills, a reasonable degree of fluency, pair and group organization skills, familiarity with certain grammatical terms etc. as the necessary intellectual content of the profession. Similarly, experiential knowledge would come to him/her from his/her own day-to-day professional practice and by the observation of other colleagues' practice. What the teacher further needs is a forum to reflect and consolidate his/her knowledge-in-action and to observe others in the profession to broaden his/her received knowledge.

In sum, the main purpose of teachers' professional training/education is to provide opportunities for their professional development by creating a common forum for developing, consolidating and broadening both kinds of professional knowledge: received and experiential.

Empirical studies. In a study aiming at investigating the effectiveness of teaching English grammar through the deductive and inductive approaches held in Jordanian schools (and universities) consisting of a sample of 100 students from the elementary school stage, Alzu'bi (2017) finds statistically significant differences in the achievements in favour of the inductive approach. He explains the achievements in terms of the training courses held by the Ministry of Education for the English language teachers on contemporary methods of teaching English. For this reason, he recommends that teachers and instructors should be encouraged to attend intensive training courses in order to make them aware of the various modern ways of teaching the English language, and to apply those ways to their classroom teaching as one of the strategies of attaining the goal of the Educational Reform for Knowledge Economy.

Similarly, Salinas's (2017) study aims at exploring the ways in which macro and micro contextual factors determine 
the construction of EFL teacher identity in educational reform. She identifies training as a means of promoting teacher identity for educational reform in Chile, and recommends that teachers should be supported with training in the micro context.

Uusiautti and Määttä (2013) review the historical development of Finnish teacher training since its beginning in the 1960s. Having assessed the contributions of the various turning points of teacher training across its history to the successful educational quality, they reach the conclusion that teacher training should be credited for Finland's success as "one of the internationally acknowledged educational superpowers" (p. 12).

Through a project involving 42 teachers (7 interviewed and 35 involved in survey data)- all attending in a programme concerning their professional development in the USA-, Crutis and Szestay (2005) investigate the following six themes constituting teachers' knowledge, beliefs and learning, contributing to their professional development through reflective practice:

- renewed enthusiasm for teaching,

- looking at teaching with "fresh eyes",

- shifts in understanding teaching,

- becoming more reflective and aware as teachers,

- enhancing the quality of student learning, and

- building professional communities.

(Crutis \& Szestay, 2005, p. 1)

Overall, experience and research in teacher training programmes suggest that training is a means of developing foreign language teachers' professional capacity, of which one is classroom teaching skills.

\section{Teaching grammar}

Grammar is the structure or system of language. As Mackay (2015) remarks, grammar deals with "...how language is organized at all levels- word, sentence, and text." (p. 20).

Customarily, grammar occupies an important position as a component in the syllabus of a language of any statusfirst, second or foreign-, although how much and how to teach it depends on which methodology is applied. This section is devoted to an overview of some commonly pronounced issues of teaching grammar.

Contents and reasons for teaching (and learning) grammar. Since grammar constitutes the system or structure of language, teaching grammar means teaching the system of the given language, and learning it means 'knowing' the system. As Ur (1996) puts it, while we are teaching grammar we should be getting our students to learn to organize, identify, produce and understand quite a large number of the bits of language knowledge and skills: form and meaning, in both spoken and written forms.

Using a language does not simply mean using the words in that language. Rather it means being able to organize words into meaningful sentences and expressions. Therefore, grammar is taught either explicitly or implicitly to enable the learner to "express him or herself in what would be considered acceptable language forms." (Ur, 2005, p. 4).

Aspects and considerations in teaching grammar. There are a number of aspects and considerations- whats and hows- in teaching grammar. This study is, however, limited to three of the most relevant ones: grammar in relation to communicative language teaching, procedures of presenting a grammar point in a language class, and deductive and inductive approaches to teaching grammar.

Grammar in relation to communicative language teaching. It can be argued that the primary focus of teaching a language should be placed on equipping the learners with abilities needed for appropriate communication. As Harmer (2008) claims, communicative language teaching (CLT) "...encourages students to communicate real meaning as a way of learning, and... emphasizes language use, especially through concentrating on language functions" (p. 270). In its essence, CLT aims at developing communicative competence, a construct Hymes (1972) defined as linguistic "capabilities of a person" (p. 282). Thus, communicative competence "includes not only knowledge of language forms but also knowledge of form-function relationships learned from the embeddedness of all language use in social life" (Cazden, 2011, pp. 366-367). Therefore, after the CLT perspective, the central aim of teaching grammar should be to develop in learners "... rules of use without which the rules of grammar would be useless" (Hymes, 1972 as cited in Hedge, 2000, p. 45). Hence, in CLT, teaching grammar is viewed as a preparatory 
activity leading to the appropriate use of language in its real life situation, not merely the formal practice of rules in isolation.

Breen and Candlin (as cited in Richards and Lockhart, 1996, p. 103) prescribe two main roles for a teacher engaged in CLT. The first is that of a facilitator: he/she facilitates 'the communication process between all participants and the various activities and texts'. The second role is as a participant: 'to act as an independent participant within the learning-teaching group'. According to them, these roles inherit such a set of secondary roles as an 'organizer' and as a 'resource' him/herself, and as a 'guide' within the classroom procedures and activities. Besides these roles, according to them, the teacher is a researcher and learner: 'to contribute in terms of appropriate knowledge and abilities, actual and observed experience of the nature of learning and organizational capacities'.

Procedures of presenting a grammar point in a language class. Harmer (2003) rephrases some key concepts often used to describe the basic whats and hows of 'popular methodology' of language pedagogy, of which one is 'procedure'. As he states, a procedure is 'an ordered sequence of techniques... first you do this, then you do that... '(p. 78). Following Harmer's concept, I would term the sequence of activities Mr. B followed at both pre-training and post-training phases of observation 'procedures'.

One important reason why a language teacher needs to plan his/her lesson is to systematize him/herself in terms of presenting the activities/tasks that he has determined in advance in the right kind of sequence so that the presentation works best in the actual workplace. There are a few of such procedures whose suitability depends on the nature and constraints of the classroom context such as, according to Hunt (2015), learner age and ability, learning preferences, class size, expectations of the concerned parties (teachers, learners, guardians, institutions, local and national regulators). As experience suggests, such factors as the amount of language exposure the students usually receive, trends of teaching and learning, teachers' and learners' belief systems, the physical set up of the classroom, materials etc. also determine the choice. This section is devoted to the review of some procedures of lesson presentation commonly used in foreign language classes.

Harmer (2003) comprehensively discusses a few of such procedures usable in a language class. They are reviewed in the following text.

PPP: This acronym stands for the sequence Presentation, Practice and Performance and is close to the British-based language teaching procedure which suggests that first the teacher introduces the situation contextualizing the language to be taught (Presentation) followed, on the part of the students, by an accurate reproduction and controlled repetition of the language which has just been presented (Practice) and finally the students are involved in using the newly learned language for making sentences of their own (Production or 'immediate creativity').

One genuine criticism labelled against this procedure is that it assumes language to be a system, subject to be fragmented and that language learning goes along straight lines- which, in our practical life, only rarely comes true. On the other hand, it is often agreed that this procedure is appropriate for beginners and elementary students rather than for higher levels.

ARC: Giving credit to Jim Scrivener as the exponent, Harmer (2003) characterizes this model as being more versatile than the PPP procedure. The key concepts in this procedure are inherent in the terms Authentic use, Restricted use and Clarification and focus. In this procedure, the 'authentic use is realized by a communicative activity. Restricted use can be provoked by students through a drill, jazz chat, elicited dialogue or guided writing' etc. Clarification language is metalanguage used by the teacher and students to explain grammar, give examples, analyze errors, elicit or repeat things, etc. The PPP procedure can be adapted as CRA in which the teacher presents a situation, clarifies the language point and institutes restricted (controlled) practice before the 'authentic' use (Harmer, 2003).

OHE/III: Referring to Michael Lewis, Harmer (2003) states that students should be allowed to 'observe' (read/listen to the language) so as to provoke them to 'hypothesize' about how the language works before going on to 'experiment' on the basis of that hypothesis. Hypothesis is a pattern similar to the III proposed by McCarthy and Carter in 1995, in which students are given examples of the language (Illustration) followed by discovery activities and questions about the language (Interaction). Consequently, students grasp new facts about language (Induction).

ESA: Recalling his own work in 1998, Harmer (2003) claims that three components will usually be present in any teaching sequence, no matter whether the lesson is long or short. According to this 'model' (Harmer's term), students need to be engaged emotionally with what is going on for their learning to be effective (Engage). He further claims that any teaching and learning element needs to have focus on how something (e. g. relative clauses, intonation patterns, a paragraph etc.) is constructed- a thing the students need to study (Study). It could be at any stage that students are encouraged to use all and/or any of the language they know (Activate). 
ESA again can have some other alternative procedures: for example, EAS ('the teacher gets the students engaged before asking them to do something'), and varieties of sequences can also sometimes, as necessary, be followed in a lesson (thus called a 'Patchwork' lesson).

PIPT: Ur (1996) suggests a general framework comprising four stages- Presentation, Isolation and explanation, Practice and Testing- which can logically be abbreviated to PIPT. 'Presentation' suggests that the teacher begins the class with a text having the grammatical structure under consideration so that the learners perceive it and take it into 'short term memory'. During 'Isolation and explanation' concentration is on the grammatical items themselves with a focus on the rules governing them, so moving temporarily away from the context. The main purpose of this stage is that the learners 'understand' the various aspects of the structure: 'what they sound and look like, what they mean, how they function' (p. 7). The 'Practice' stage is concerned with transferring the learners' currently gained knowledge of the structure(s) from short-term to long-term memory. Therefore, at this stage, a series of exercises are done in the classroom or/and as home assignment. Finally, the 'Test' stage involves learners in demonstrating - to themselves or to the teacher- how well they have learned the material.

I am personally convinced with Harmer's (2003) view that none of the 'models' (his term) could serve as... "the central pack of good teaching. The goal is flexibility, not rigidity" (p.84). Yet, as the trainer, I attempted to shape the participants through a demonstration dominantly aligned with the PPP procedure for a few reasons. First, the ultimately targeted beneficiaries were the secondary level students- teenagers by age and could reasonably be labelled as elementary learners in the EFL context of Nepal. Secondly, the amount of exposure to English that those students are given is roughly four and a half hours a week (six periods of 45 minutes each). Thirdly, as I reasoned, such factors as the learners' age and ability, learning preferences, class size, expectations of the concerned parties (Hunt, 2015), the teachers' mindsets and beliefs (Poudel, 2017), the learners' expectations shaped by the foreign language teaching trend traditionally rooted in Nepal (teacher-led, rule-glued and grammar translation-based), the institutional policy and programmes, the physical set up of the classroom, materials etc., would come as constraints against the other procedures (mentioned above) which I thought were basically too demanding in terms of their assumptions regarding those factors.

Deductive and inductive approaches to teaching grammar. When one sweeps through the literature of language teaching, one is likely to get confused with the various terms inconsistently used to refer to the delivery process of grammatical items in a language class: so, are inductive and deductive 'approaches' or 'methods' or 'ways' or 'strategies' or even something else? I use the term 'approach' to refer to them since I am convinced that induction and deduction are both assumptions describing the way language knowledge/ability is acquired and making statements about the conditions that promote successful language learning- all that an approach (unlike a method, procedure or technique) does (Harmer, 2003).

The deductive approach is to a large degree congruous with the 'focus-on-forms' instruction, that is, "...the instruction that seeks to isolate linguistic form in order to teach them one at a time... [as in] a structural syllabus" (Ellis, 2008, p. 870) whilst the inductive approach tends to be in close proximity to the 'focus-on-form' instruction which, according to him, is the classroom instruction in which "attention to form arises out of meaning-centred activity derived from the performance of a communicative task" (p. 255). The deductive 'method' (Alzu'bi's term) is a 'rule-driven', 'top-down' one and, contrarily, the inductive 'method' is a 'rule-discovery', 'bottom-up' one (Alzu'bi, 2015). Likewise, Haight, Herron and Cole (2007) conceptualize that in the deductive approach,"...students are taught to focus on the rule before using the structural forms" and in the inductive approach,"...they are taught to use the grammatical structure in a functional practice session before the rule presentation" (p.289).

Table 1. Procedural Distinctions between Deductive and Inductive Approaches (Adapted from Allen \& Valette, 1972)

\begin{tabular}{|c|c|}
\hline Deductive approach & Inductive approach \\
\hline Statement of the rule or pattern, ${ }^{*}$ & Presentation of examples, \\
\hline Sample sentences that students repeat, & Oral or written practice, \\
\hline $\begin{array}{l}\text { Ample opportunity for students to practice the } \\
\text { new pattern }\end{array}$ & $\begin{array}{l}\text { Generalization of the rule that grows out of } \\
\text { the previous activity* }\end{array}$ \\
\hline (* The first presentation is usually made orally.) & $\begin{array}{l}(* \text { Either the teacher states the rule or the students } \\
\text { formulate it) }\end{array}$ \\
\hline
\end{tabular}


In sum, the most explicit distinction between the deductive and the inductive rests on the order of the placement of the metalanguage (rule) and illustration (examples) during lesson presentation: the former is the 'rule-first and then the examples' approach and the latter is the 'examples-first and then rule' approach (Table 1). The deductive approach can be characterized as a traditional one that assumes language learning as an intellectual practice to be carried out by learners whereas most researchers' advocacy aligns with the inductive approach (e. g. Alzu'bi, 2017) that tends to foster language acquisition through discovery rather than learning the dry rules to be applied later on.

\section{Conceptual framework}

The study was fundamentally associated with two constructs interacting with each other: language teacher training and teaching grammar. It viewed teaching grammar from the perspective of teacher training. The review relevant to these two constructs provides useful insights into developing a conceptual framework (Figure 1) thereby providing necessary 'lenses' for analyzing the data leading ultimately to the conclusion drawn on the findings.

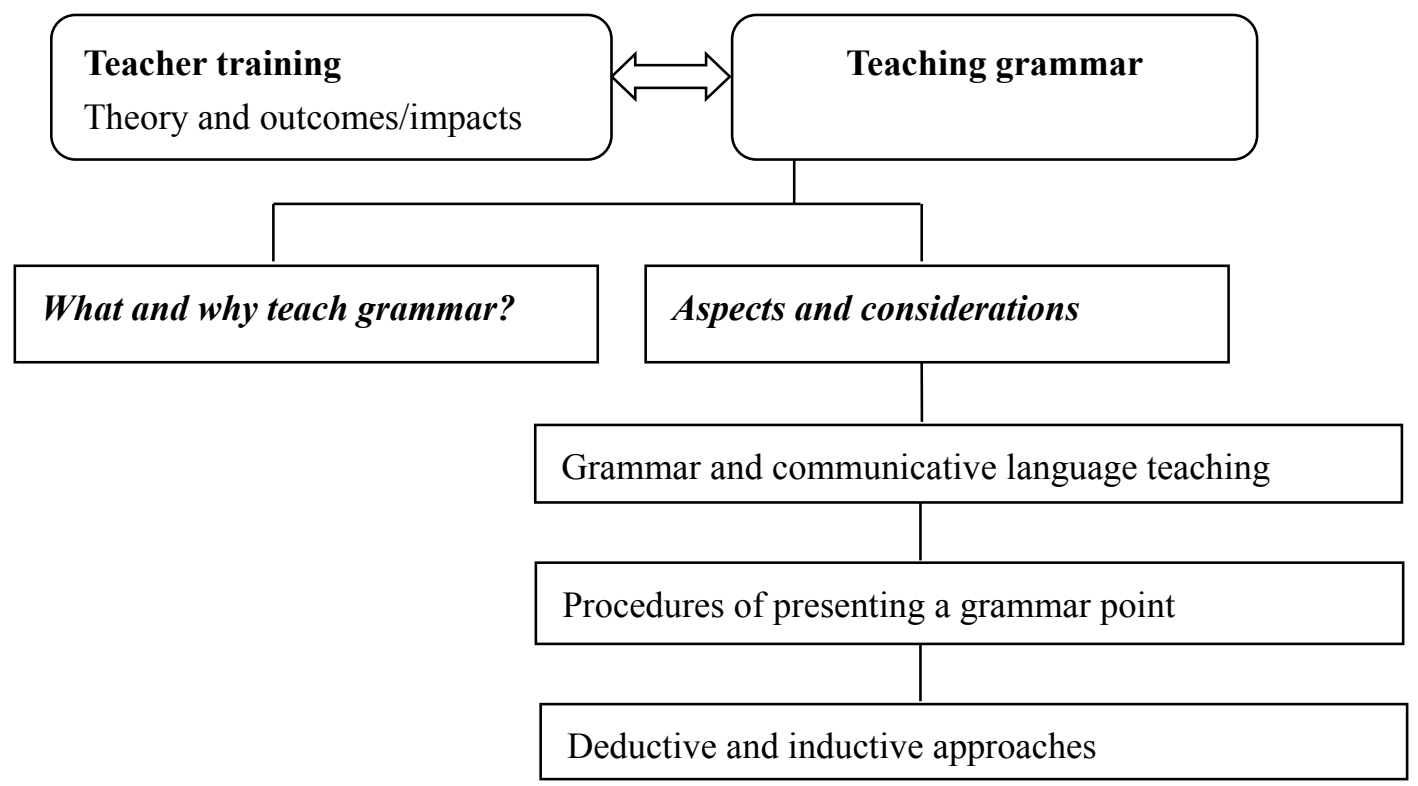

Figure 1. Conceptual Framework of the Study (Lens Providers)

\section{Methodology}

This study was fundamentally guided by the qualitative paradigm of inquiry, more specifically action research, emerging from a case study. Therefore, the key notions 'case study' and 'action research' as conceptualized in this study are elaborated in the lines below.

Case study: In this study the case study was conceived as an approach which is "unique (in the sense of singular) and bounded" (Casanave 2015, p. 129), and "...investigates one person...in depth...with a goal of understanding a phenomenon or a process as exemplified by the person" (Swanborn, 2010, p. 218).

Action research: A very useful ('useful' at least for this study) concept of action research comes from Burns (2010). Quoting from van Lier (1996), she defines action research as a "...small scale intervention in the functioning of the real world and a close examination of the effects of such intervention" (p. 4). Similarly, referring to Kemmis and McTaggart (1998) Burns (2010) suggests four 'broad phases' in which action research is conducted: Planning (identifying the problem and planning for action to bring about improvements in the area/context), Action ( involving some deliberate interventions into the teaching situation over an agreed period of time), Observation (observing systematically the effects of the action, documenting the context, actions and opinions of those involved... data collection phase where the researcher uses 'open-eyed' and 'open-minded' tools to collect information about what is happening), and Reflection (reflecting on, evaluating and describing the effects of the action in order to make sense of what has happened and to understand the issue that you [the researcher] have explored more clearly... to improve the situation even more... or to share the 'story' of your [the researcher's] research).

I was particularly attracted by Mr. B's (a secondary level EFL teacher with an experience of seven years- a 
participant) query "Which method of teaching grammar should be adopted- deductive or inductive, or still any other methods?" So, to identify the actual problem I observed four of his classes (pre-training observations) as the case study. However, as soon as the problem was identified, I realized that it was not where my inquiry ended. Therefore, I planned two further actions: the intervention during the TPD refresher, and post-training observations to see whether and what improvements the participant would demonstrate again in his EFL classes. In other words, this was where and how my action research began.

As can be seen in Figure 2, the single-unit longitudinal study comprised three key components in its procedure: pre-training observations, intervention and post-training observations.

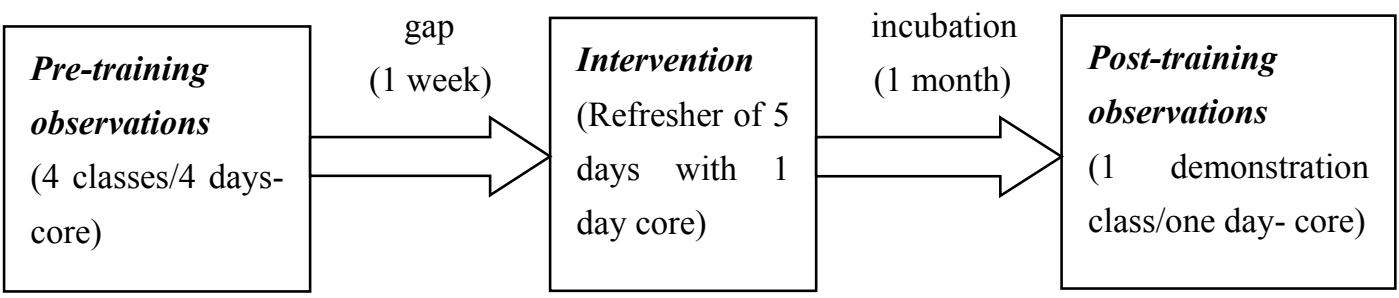

Figure 2. Key Study Procedures

The study process spread roughly over seven weeks with a core of five days: four classes (one each day) for the pre-training observations; a 'gap' of one week between the pre-training observations and the intervention (the TPD refresher); five days (with one core) for the intervention and an 'incubation' of one month between the intervention and the post-training observations. Indeed, the pre-training observations phase was the case study part of the research and the intervention and the post-training observations were the action research part.

The methodology of each procedure is briefly highlighted below.

Pre-training observations: Upon Mr. B's consent, I observed four of his classes in Grade 9 (spreading over four days) until a total picture of the activities used in teaching a grammar point was obtained, simultaneously recording the typical teaching and learning activities as data in the form of diary notes a week prior to the TPD refresher.

Intervention: In this study, the activities in the TPD refresher, particularly the demonstration on the inductive and deductive approaches, were applied as the intervention.

Post-training observations: As soon as the refresher was over, I talked to Mr. B and, so arranged an observation class in the same setting as the pre-training observations. An interval of one month between the refresher and the post-training observations was negotiated because we estimated that it would take a month of time for the students (and the teacher?) to adopt to the new 'styles' (his term) of teaching and learning Mr. B had acquired during the TPD refresher.

In both pre-training and post-training observations I, the observer, sat alone at the back of the class trying my best to be as undisruptive as possible noting down in a diary the most explicit of the classroom activities and their impacts intending to ensure my role as a non-participant observer for the unstructured observation (Cohen, Manion \& Morrison, 2007).

To confirm whether or not the differences between the pre-training and post-training observations in Mr. B's teaching 'styles' were the consequences of the intervention (the TPD refresher)- in other words, to triangulate - we (Mr. B and I) held an informal talk after the post-training observations.

The detailed information obtained through these procedures is provided in the section 'The Context and the Case' above.

Being guided by the conceptual framework as the lens provider for comparing and contrasting the pre-training and post-training observations the data were analyzed to reach the conclusion.

\section{Results and Interpretation}

Using the conceptual framework as the lenses the pre-training and post-training observations were compared and contrasted to draw the major distinctions between them. Table 2 displays those results of the comparison and contrast (see Appendices for details). 
Table 2. Major pre-training and post-training observations: Compared and Contrasted

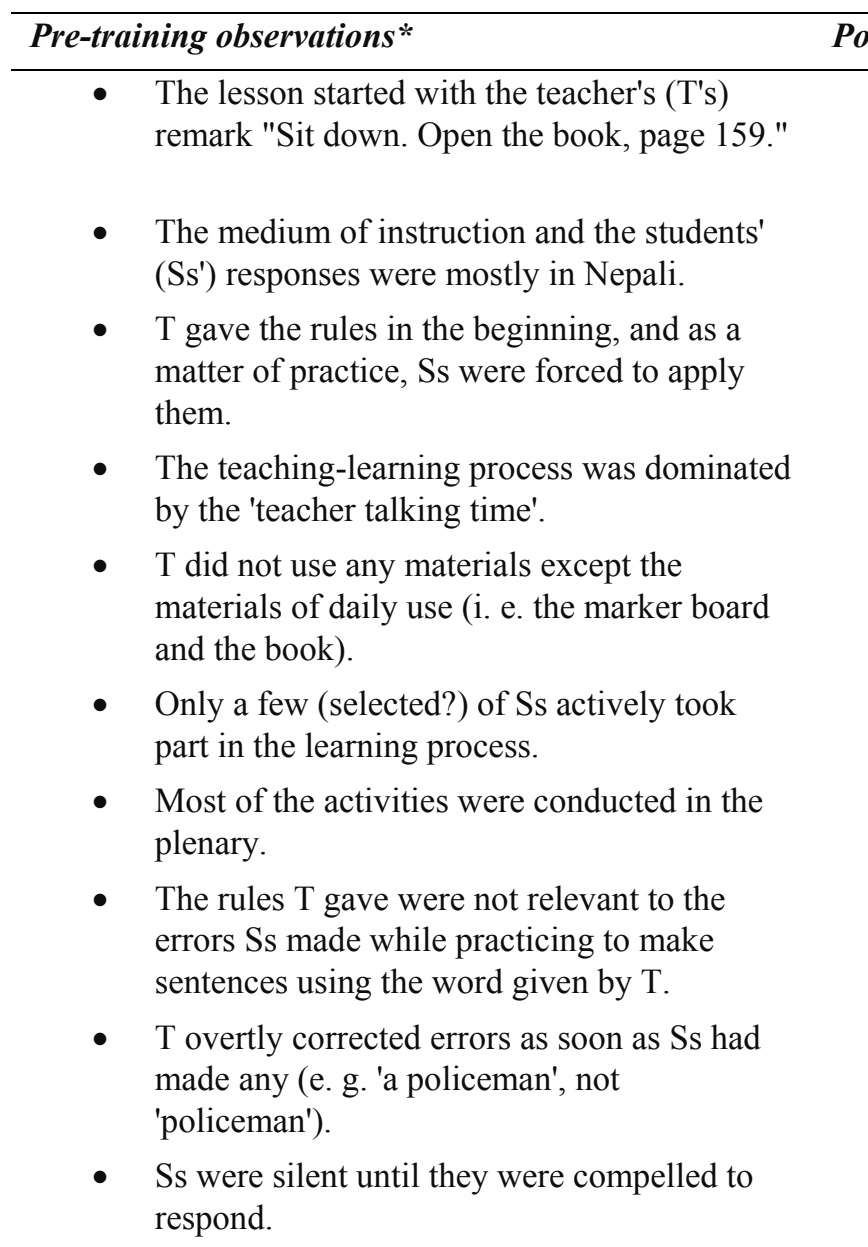

Post-training observations **

- $\quad$ The lesson started with the mutual greeting "Good morning. Sit down" initiated by the teacher $(\mathrm{T})$.

- $\quad$ The medium of instruction and Ss' responses were mostly in English.

- $\quad \mathrm{T}$ gave a presentation based on the real life situation. Then finally Ss were encouraged to generalize the rules themselves.

- The teaching-learning process was dominated by the 'student talking time'.

- $\quad$ T used flashcards and a chart as 'elicitors' for practice.

- Most of Ss were actively engaged in the learning process.

- Some of the activities were conducted in the plenary and some in groups.

- $\quad \mathrm{T}$ did not give any overt rules initially.

- $\quad$ T helped Ss in case Ss experienced difficulty/confusion or made errors.

- Nearly all Ss spontaneously took part in the learning process (problem solving etc.)

**Relevant data given in Appendix 2.

[Note: No evidence of 'unfavourable' environmental factors functioning as hindrances to the teaching-learning process was found throughout the observations (both), as supported by Mr. B's (T's) remark made at the informal talk held immediately after the post-training observations (see Appendix 2).]

Using the ideas in the conceptual framework (Figure 1) as the lenses, we can make some sense of the distinctions between the two observation phases as presented in Table 2. First, Mr. B used the deductive approach to teaching grammar before he had participated in the TPD refresher but he used the inductive approach after it. Secondly, as the data reveal, the lesson activities at the pre-training observations phase were not as clearly observable/definable as at the post-training observations phase. The lesson at the post-training observations phase was organized around the PPP procedure (see Appendices). Likewise, at the pre-training observations phase Mr. B and the students both spent most of the class time talking in Nepali, the mother tongue, but they were found interacting in English, the target language, at the post-training observations phase.

The data also demonstrate that Mr. B's class activities were not as varied and lively before the training as they were after it (see Appendices). Also, as the data reveal, the class was regarded by Mr. B as a 'lockstep' setting at the pre-training observations phase whilst he regarded it as being collaborative as well as individualistic as necessary at the post-training observations phase. What the data also suggest is that, at the pre-training observations phase, Mr. $\mathrm{B}$ explained the rules at the beginning of the lesson, which seemed to be incomprehensive whereas at the beginning of the post-training observations phase he presented a few sentences in a real-like situation in order for Ss to internalize the rules inherent in them.

Mr. B reflected himself as the authority and corrector of the Ss' errors at the pre-training observations phase but at the post-training observations phase he demonstrated himself as a facilitator. Thus, the teaching-learning activities 
were predominantly teacher-centered at the pre-training observations phase. Consequently, Ss were found less responsive (silent in most cases) at the pre-training observations phase but at the post-training observations phase, they were found far more responsive.

Finally, the pattern of teaching observed at the pre-training observations phase was very similar to the traditional model of language teaching, leading to 'teach about the language'. Nonetheless, the pattern of teaching observed at the post-training observations phase was similar in many ways to the modern communicative language teaching, leading to 'teaching the language' itself.

\section{Discussion and Reflection}

The study was conducted amid some serious limitations. First, the sample was a single secondary level EFL teacher. The data were obtained from his five classes of which four were observed before the TPD refresher without any pre-arrangement for demonstration (but upon his consent), and one was observed as demonstration after it. On both of these occasions, the same teaching item of grammar- the simple present- was taught. The observations were conducted with an aim to see whether, and to what degree, the output of the TPD need-based refresher would be reflected in the real classroom situation. Secondly, the measures used to guard against the threats between the 'variables' were relatively weaker. For example, the same lesson taught a second time would naturally go more effectively and faster in terms of both teacher and learner performances than when it was taught the first time. After all, the findings were generalizations but not the outcomes of statistical precisions.

In spite of the limitations, the generalizations are of great significance. The findings have brought into light a number of the instances of 'paradigm shift' in Mr. B's (the teacher's) performance. Such shifts include changes in most pronounced aspects and considerations of teaching grammar such as from deduction to induction, from 'teaching about the language' to 'teaching the language' itself, from the absence of teaching aids in the EFL teaching to their presence, from teacher-centeredness to learner-centeredness, from a traditional dictator model teacher to a modern humanistic, communicative language teaching model teacher, and from passive learners to actively participating learners. In fact, we can argue that these shifts were the transformations brought about by the TPD refresher. Thus, as the study suggested, there was a much greater degree of reflection of the TPD refresher in the real situation than CERID (2005) reported (50\%). Meanwhile, the study found no clear evidence in support of the claim made commonly by the English teachers that the classroom 'environment' was 'not favourable' for teaching EFL in Nepal. Thus, according to this study, this claim still remained a hypothetical assumption requiring further research.

However, we can also argue that transforming to this degree was possible under at least three conditions. First, Mr. B was potentially competent in what Wallace terms 'acquired knowledge' as an EFL practitioner. If he had been 'unable even to write an application on the spot', of course, he would not have been able to demonstrate all the transformations. Secondly, he was a motivated professional with a sense of bringing about those positive changes to his teaching: his need was clearly focused on the problem encountered while teaching grammar, and also had reflected himself during the training that applying the inductive approach would be possible 'if tried properly and patiently'. Thirdly, the trainer had also put ample dedication to his assignment in that he had carried out the case study and planned accordingly for the training session with an anticipation of the transformation of the EFL class(es) through the TPD refresher. The training session was not at least somehow like what a teacher, my childhood friend, once in a private talk had remarked, "We came this afternoon; we will get the 'pocket money' tomorrow; and having completed the three-day training, we will return early in the morning day after tomorrow!"

\section{Conclusion}

As can be seen from the data (see Appendices) Mr. B followed a procedure which was very close to the PPP, which seemed to suit the foreign language (English) proficiency level of the learners. Since the most explicit (if not the only) factor that intervened between the pre-training and post-training observations was the 5-day face-to-face need-based TPD refresher, we can infer that the main cause of the changes reflected in the classroom was the output of the TPD refresher. Therefore, we can suggest that teachers reflect best in the areas around their needs which are treated.

The teacher/trainee needs to be qualified in terms of 'received knowledge' (Wallace, 2010) and competent in the foreign language. The training needs to be need-based, so the programme syllabus should come from teachers' demands, so as to address their motivation arising from their reality.

This research consolidates the further need for timely teacher training/refreshers based primarily on the teachers' genuine needs to bring about transformations in foreign language teaching and as part of their professional 
development as the other findings in this area suggest (e. g. Wallace, 2010; Salinas, 2017; Alzu'bi, 2017; Crutis \& Szestay, 2005).

Training is necessary when qualified teachers know the theory but they don't know the action. Thus the main function of teacher training is as an opportunity provider for developing skills and competence needed for the academically qualified teachers' professional life.

The final remark would then be that, given all these conditions, transforming (foreign) language grammar classes is possible through timely need-based teacher training and its judicious reflective practice in the classroom teaching.

\section{Acknowledgements}

This article grew in course of my PhD pursuit which was encouraged by the UGC (Nepal) fellowship for PhD students (2016) and was inspired by the useful and encouraging insights from Dr. Binod Luitel, my PhD supervisor. I heartily acknowledge both of them as well as the anonymous reviewers for their valued suggestions/feedback.

\section{References}

Allen, E. D., \& Valette, R. M. (1972). Classroom techniques: Foreign languages and English as a second language. USA: Harwart Brace Joranovich Inc.

Alzu'bi. (2015). Effectiveness of inductive and deductive methods in teaching grammar. Advances in Language and Literary Studies, 6(2), 187-193. https://doi.org/10.7575/aiac.alls.v.6n.2p.187

Burns, A. (2010). Doing action research in English language teaching. New York: Routledge.

Casanave, C. P. (2015). Case study. In Patridge, B., \& Phakiti, A. (Eds.), Research methods in applied linguistics, pp. 119-135. London: Bloomsbury Academic.

Cazden, C. B. (2011). Dell Hymes's construct of communicative competence. Anthropology \& Education Quarterly, 42(4), 364-369. https://doi.org/10.1111/j.1548-1492.2011.01144.x

Cohen, L., Manion, L., \& Morrison, K. (2007). Research methods in education. London: Routledge.

Crutis, A., \& Szestay, M. (2005). The impact of teacher knowledge seminars: Unpacking reflective practice. TESL-EJ, 9(2), 1-16.

Ellis, R. (2008). The study of second language acquisition. Oxford: Oxford University Press.

Haight, Herron \& Cole (2007). The effects of deductive and inductive instructional approaches on the learning of grammar in the elementary foreign language classroom. Foreign Language Annals, 40(2), 288- 310. https://doi.org/10.1111/j.1944-9720.2007.tb03202.x

Harmer, J. (2003). The practice of English language teaching ( $3^{\text {rd }}$ ed.). Essex: Longman.

Hedge, T. (2000). Teaching and learning in the language classroom. Oxford: Oxford University Press.

Hunt, J. R. (2015). Approaches to teaching grammar. Hitotsubashi Journal of Arts and Sciences, 49, 49-53.

Hymes, D. H. (1972). On communicative competence. In Pride, J. B. and Holmes, J. (Eds.), Sociolinguistics: Selected readings, pp. 269-293. Harmondsworth: Penguin.

Mackay, R. (2015). A basic introduction to English language teaching. Oxford: Oxford University Press.

National Centre for Educational Development (2009). TPD handbook. Sanothimi, Bhaktapur: NCED.

Poudel, K. K. (2017). Functions of language: A historical overview and the Nepalese context. Nepalese Linguistics, $32,57-66$.

Richards, J. C., \& Lockhart, C. (2010). Reflective teaching in second language classrooms. Cambridge: Cambridge University Press.

Richards, J. C., \& Renandya, W. A. (2011). In Richards, J. C. and Renandya, W. A. (Eds.), Metodology in language teaching: An anthology of current practice (Section 5), pp. 93-94. Cambridge: Cambridge University Press.

Salinas, D. (2017). EFL teacher identity: Impact of macro and micro contextual factors in Education Reform Frame in Chile. World Journal of Education, 7(6) 1-11. https://doi.org/10.5430/wje.v7n6p1

Swanborn, P. (2010). Case study research: What, why and how? Los Angeles: Sage.

Ur, P. (1996). Grammar practice activities. Cambridge University Press. 
Uusiautti, S., \& Määttä, K. (2013). Significant Trends in the Development of Finnish Teacher Training Education Programs (1860-2010). Education Policy Analysis Archives, 21(59). Retrieved 2. 13. 2018, from http://epaa.asu.edu/ojs/article/view/1276.

Wallace. M. J. (2010). Training foreign language teachers: A reflective approach. Cambridge: Cambridge. University Press.

\section{Note}

Note 1. In some cases, the word 'foreign' in the phrase 'foreign language' is parenthesized to denote that the given phenomenon may also hold truth in language teaching in general.

\section{APPENDICES (The classroom pictures)}

\section{Pre-training observations}

(Note that almost all of the activities were conducted in the Nepali language)

Teacher (T): (Orally) Sit down. Well, you all, open your book on page 159. Here, you are going to learn about the simple present tense. The simple present tense is used to say what people generally do. The structure of the simple present tense is like this (writes on the board): Sub. $+\mathrm{V}_{1} / \mathrm{V}_{5}+\mathrm{Obj}$.

You know if the subject is singular the verb takes the $\mathrm{V}_{5}(-\mathrm{s} / \mathrm{-es})$ form, and if the subject is plural the verb takes the $\mathrm{V}_{1}$ (root) form.

The next rule is- if the verb is the $V_{1}$ form, we use 'do' while changing the sentence into a question or negative, but if it is the $\mathrm{V}_{5}$ form we use 'does'. Clear?

Students (Ss): (A few of them nod their head as a response. The rest of them remain silent.)

T: Now, let's use the rules and do Exercise 6. O. K.?

Ss: O. K. Sir.

T: 'Policeman' (writes on the board). Is this word singular or plural?

Students (Ss): (Silent)

T: It's singular because there is only one. 'Shopkeepers' is plural because there are more than one. So 'policeman' takes an -s/-es verb in the affirmative, and 'does not' in the negative because it is singular. 'Shopkeepers' takes the $\mathrm{V}_{1}$ form in the affirmative, and 'do not' in the negative because it is plural, isn't it? So, make a sentence using 'policeman' as the subject and: catch a thief (affirmative) and teach students (negative).

Ss: (Silent)

T: So, Bimal?

S: (In Nepali) Sir, I have written: 1) Policeman catches a thief. 2) Policeman does not teach students.

T: 'A policeman'; not 'policeman'. Uttam?

S: A policeman catches a thief (affirmative). A policeman does not teach students (negative).

T: Good. Now, 'Shopkeepers'. It's plural, isn't it? Use: sell goods (affirmative) and dig a farm (negative). Who can say what?

S (Uttam): (Reads his answer). Shopkeepers sell goods (affirmative). Shopkeepers do not dig (negative).

T: (In the plenary): Is Uttam correct?

Ss: (Silent)

$\mathrm{T}$ : He is correct.

He assigns, as homework, the rest of the words given in the list in the book (i. e. little kids, umpire, teacher, tourists, rich people, dramatists) with a necessary clue for each. Most of the students, not all, write down the clues in their exercise books. (The bell rings.)

$++++++++++++++++++++++++++++++++++++$ 
As the class was over -and we were outside- Mr. B asked for my 'responses' to his class activities. I did not respond to his query comprehensively but deliberately twisted the conversation because, I knew, he was going to be a participant (trainee) in the need-based TPD refresher training organized by ETC, Ilam.

(Immediately after the completion of the training, I begged to be permitted to revisit Mr. B's class, and also asked him if he could reteach the same grammar point as in my previous observation, i.e. the simple present tense, in the new way as they had known in the training session. Mr. B wholeheartedly agreed to my proposal and the date was agreed on- tentatively one month later.)

\section{Post-training observations}

(Note that almost all activities were conducted in the English language in clearly identifiable steps.)

$\underline{\text { Step I }}$

T: Good morning Class 9.

Ss: Good morning Sir.

T: Well, we are going to play a 'who does what?' game today. But before that, I am going to tell you what people do in my village. Are you ready to listen?

Ss: Yes, Sir.

T: (Orally) Well then. In my village, many people live together and do different jobs. The farmers work on their farms. They grow crops and vegetables. The children go to school and read. They do not stay back home on school days, I mean... school opening days. There is a postman in the village. He goes to his office and sometimes brings letters to the villagers. He does not open the letters himself. There are some teachers who teach at the local school. Nearly 500 students read at that school.

$\underline{\text { Step II }}$

T: Well. Students, now look at this chart (draws a chart on the board). Now tell me 'who does what' in your family.

\begin{tabular}{|l|l|l|}
\hline Who? & $\checkmark$ & $\times$ \\
\hline Father & & \\
\hline Mother & & \\
\hline I & & \\
\hline The children & & \\
\hline
\end{tabular}

$+++++++++++++++$

T gets four students to fill in the table- one each. Then he gets some other (8) students to make sentences with the clues. He helps in case they need any until finally they make such sentences as follows orally:

Father earns money. He does not cook meals. Mother cooks meals. She does not climb up a tree.

I go to school. I do not earn money. The children play. They do not go to market.

$\underline{\text { Step III }}$

( $\mathrm{T}$ divides the class into six groups, A-F)

T: This time I will show and you'll have to say. O. K.?

Ss: O. K. Sir.

T: (Holds a flashcard high displaying 'Policeman', and provides some time). Group C!

$\mathrm{S}$ (from Group C): A policeman catches a thief. He does not work on a farm.

T: Good. (Holds a flashcard high displaying 'Shopkeepers', and provides some time). Group F!

$\mathrm{S}$ (from Group F): Shopkeepers sell goods. They do not teach.

T: Good.

( $T$ uses the same 'pattern of teaching' with the rest of the groups of the students and the rest of the words- little kids, umpire, teacher, tourists, rich people, dramatists. Then finally he reassembles the students into individuals.)

$\underline{\text { Step IV }}$ 
T collects Ss' generalizations to make the rules, and sums up on the board in the following way:

A policeman/he/she $\rightarrow$ works/plays, or does not work/does not play.

$\mathrm{I} /$ they/children $\rightarrow$ work/play, or do not work/do not play. (The bell rings.)

$$
++\quad++\quad++
$$

As the class was over-and we were outside- I managed an informal tea-talk as a post-observation discussion with Mr.

B. This went like the following:

Trainer (Tr): (In Nepali) Did you encounter any 'environmental factors' (i. e. the so-called 'low proficiency of the learners and socio-political situation') that hindered you from teaching that effectively?

T: Well, it turns out to me that the classroom environment is basically subject to management or creation. But it takes a little time, effort and patience.

Tr: Sure. You can make it up at least for your purpose. 